\title{
Benefits of Smart Grid Solutions in Open Electricity Markets
}

\author{
Nenad Katic \\ University of Novi Sad, Trg Dositeja Obradovica 6, 21000 Novi Sad, Serbia, \\ e-mail: nenad.katic@telventdms.com
}

\begin{abstract}
Smart Grid Solutions include different technologies to improve the efficiency of electricity distribution network operations (e.g. distribution automation systems, smart metering, home automation and demand response solutions). The benefits arising from the implementation of distribution automation systems are investigated and evaluated in this article (e.g., the reduction of power losses and the reduction in outage costs and network development costs), taking into consideration the environment of an open electricity market. The investment costs and operation and maintenance costs for the deployment of such systems are analysed as well. Finally, a comparison of the benefits and costs is provided, and relevant conclusions to achieve profitability of the distribution automation systems are considered.
\end{abstract}

Keywords: Cost Benefit Analysis; Distribution Automation System; Open Electricity Market; Power Distribution; Smart Grid Solutions

\section{Introduction}

In an open electricity market (a deregulated electricity industry sector), Power Distribution Companies (PDC) become "service providers", as regulated Utilities, providing the "transport" of electric energy from the transmission side to end consumers (customers). On the other side, the sale of electric energy is provided by competitive "energy providers" or directly negotiated between large customers and producers. In such a new environment, PDCs have limited revenue and are firmly controlled by regulators and technical regulations on the quality and reliability of the electric energy supply.

The PDC's service, as a monopoly, is a regulated business and the revenue comes from the "the charge for use of the system". All system users (power consumers, customers) connected to the power distribution system pay for the service of energy transport to connection (consuming) point. The revenue of each PDC is controlled (regulated) by the regulator, applying one of the common methods in the deregulated electricity industry [1] - [4]: 
a) Rate of Return: Annual revenue of PDC is established with reasonable operating costs and a certain return on asset approved by the regulator:

$R_{t}=\sum_{i=1}^{n} p_{i} \cdot q_{i}=\sum_{j=1}^{m} \operatorname{Cost}_{j}+r \cdot V_{\text {assets }}$

$p_{i}-$ unit price of delivered service $i$,

$q_{i}$ - estimated number of service units $i$, to be delivered in a considered regulatory period,

Cost $_{j}$ - operating costs of class $j$,

$r$-rate of return approved by regulator,

$V_{\text {assets }}$ - value of assets approved by regulator.

The disadvantage of this method is that there is not enough incentive for the regulated company to improve the efficiency of operation; rather the company focuses on approving assets with the regulator and increasing the rate of return.

b) Price cap: incentive method to improve the efficiency of operation, because it is impacted with "efficiency factor" set by regulator:

$P_{i, t}=P_{i, t-1} \cdot\left(1+\frac{R P I-X}{100}\right) \pm Z$

$P_{i, t}-$ unit price of delivered service $i$ in the next year/ period $t$,

$P_{i, t-1}-$ unit price of delivered service $i$ in previous year/ period $t-1$

RPI - Retail Price Index in \%,

$X-$ efficiency factor in $\%$,

$\mathrm{Z}$ - corrective factor for external deviations.

If the efficiency factor is higher, then the PDC has a strong incentive to improve the efficiency of operation and produce profit, which stays in company since the regulatory period is normally several years.

c) Revenue cap: incentive and more sensitive method assuming changes of transported energy and number of customers:

$R_{t}=\left(R_{t-1}+F_{\text {client }, \text {. }} \Delta\right.$ Client $_{t}+F_{\text {energy }, t} . \Delta$ Energy $\left._{t}\right) \cdot\left(1+\frac{R P I-X}{100}\right) \pm Z$

$R_{t}-$ maximal revenue in the next year/ period $t$,

$R_{t-1}-$ revenue in the previous year/ period $t-1$, 
$F_{\text {client, } t}, F_{\text {energy,t }}-$ correction factors assuming changes in the number of customers and delivered energy in period $t$,

$\Delta$ Client $_{t}, \Delta$ Energy $_{t}$ - estimated changes in the number of customers or delivered energy in period $t$.

d) Benchmarking: the comparison of performance indices between similar regulated companies in a given region.

In the next step, the approved revenue is recalculated on "network usage tariffs" based on one of the common methods used in the deregulated electricity industry:

a) Postage stamp method: in this simple method, all transportation costs (regulated revenue) are distributed on service units (delivered energy, demand power, connection power, etc.) for all network users, regardless of the point of connection. The same network tariff is paid, only multiplied by the quantity of delivery.

b) MW mile method: the tariff depends on the distance between the points of generation and consumption, but not on the real impact of the transaction on the system (load flow).

c) Modulus of use: in this case, load flow calculation results are accounted, and the real impact of each transaction on the system.

The regulatory methods commonly applied in PDCs are Rate of Return, as a simpler method for young electricity markets (e.g. Serbia [5]), and Revenue Cap as a more complex method for developed markets (e.g. Portugal, Norway [6], etc.), whereas tariffs in distribution are normally calculated with the simple postage stamp method.

In any case, the PDC is responsible for covering power losses in the distribution network, and only a certain level of losses is accounted in approved costs. If the PDC operates with higher losses than approved, the additional costs can be paid only from PDC's profit; but if it operates with lower losses, the PDC's profits will increase. Regarding the reliability of supply, it is penalized either by incentive revenue cap methods or by direct compensation to customers under certain conditions. If the PDC operates with higher efficiency and better reliability indices, additional profit will be generated; but with worse reliability, profit will be reduced.

Under the pressures of regulated and limited revenue, the PDCs in the deregulated electricity industry sector have to invest in advanced technologies, known as Smart Grid Solutions, in order to improve the quality and reliability of supply and to reduce power losses in the distribution power lines. Smart Grid Solutions should improve the efficiency and reduce the costs of network operation. The real challenge is the quantification of the benefits provided by Smart Grid Solutions and the comparison of these benefits with related costs, in order to estimate the real profitability of such investments, which is the main subject of this article. 


\section{Smart Grid Technologies}

Smart Grid Solutions (SGS) encompass different technologies targeted to improve the efficiency of the distribution network operation:

- Distribution Automation Systems (DAS),

- Advanced Metering Infrastructure (AMI) and remote meter reading and data management,

- Smart power equipment with improved operation characteristics,

- Distributed Generation management, Energy Resources management (e.g. battery storages, electrical vehicles) and Demand Response systems, which can affect distribution network operation.

Distribution Automation Systems (DAS) implementation benefits and costs are analysed in this article. DAS typically consist of the following modules:

- Centralized Control System Software, including basically three systems: SCADA (Supervisory Control and Data Acquisition System), DMS (Distribution Management System) and OMS (Outage Management System), integrated in the solution.

- Centralized Control System Hardware, including typically Main Data Center servers, Disaster Recovery Data Canter servers and User workstations.

- A communication system to support high speed transfer of data over wide areas.

- Field execution system - remotely controlled equipment in field (load breaking switches and regulators with motor drives) with a communication subsystem (remote terminal units and radio or line communication modems).

The central intelligence of DAS is the Distribution Management System (DMS), a (mathematical) modeling of the power network, a set of calculation engines and algorithms to provide network operation optimization, analysis, reporting and long-term planning. The DMS calculation results applied in field by communication and field devices can provide important targets to the PDCs:

- Reduction of power losses, optimizing power flow and voltages in power network,

- Improved reliability of supply, reducing outage times with advanced Fault Management technologies,

- Improved power quality, with optimal Voltage/Var regulation,

- Overall improvement of customer services,

- $\quad$ Significant revenue increases. 
Advanced DMS provides an efficient user interface for power network control, monitoring and visualization (schematic and geographical), comprehensive technical database, real-time and simulation (study) environments, historical data access and storages, web technologies, as well as a wide set of power functions:

- Fundamental power functions for the calculation of power flow and the network operation state, which are typically "resident" functions automatically triggered by the software system,

- Network operation functions for switching scheduling and execution, management of faults and emergency situations, typically used by operators in the control room for the real-time network operation,

- Network optimization functions for the optimization of power flow and voltages, typically used by engineers in support of the control center, for short-term operation planning,

- Network analysis and Reporting functions for the analysis of short-circuits, relay protection settings, contingency problems, equipment rating, and harmonic pollution, and to provide reports about outages, power losses, etc., typically used by engineers in simulation mode,

- Network Development functions for (medium-term) maintenance planning and long-term analysis of the network design, construction and development, typically used by engineers in investment and planning departments.

\section{DAS Benefits}

Benefits, achieved in one PDC after DAS implementation are analysed and evaluated in this section. The benefits are analysed for one example of a live distribution network (DN) presented in Figure 1. The DN is supplied by one HighVoltage (HV) Substation, $110 / 35 \mathrm{kV}$, then by four $35 \mathrm{kV}$ power lines supplying four Distribution Primary Substations (DPS) at $35 / 10 \mathrm{kV}$, and by 40 outgoing 10 $\mathrm{kV}$ feeders. The medium voltage (MV) $10 \mathrm{kV}$ distribution network has 350 kilometers of underground and overhead power lines, 360 Distribution Secondary Substations (DSS) at $10 / 0,4 \mathrm{kV}$ with a total of 90 MVA transformer power. The DN supplies 25,000 consumers (customers). The peak power of the DN is approximately $50 \mathrm{MW}$, with injected electrical energy annually into the DS (EEIA) of approximately $200 \mathrm{GWh}$, on the $110 \mathrm{kV}$ (purchase) side.

The PDC is a regulated company and revenue is approved by a regulator, using, for example, the revenue cap method. The PDC earns revenue by charging consumers for the use of the distribution system, applying tariffs calculated with the postage stamp method. Customers pay a specific tariff according to consumption type, based on the quantity of consumed $\mathrm{kWh}$, regardless of the connection point location. According to the definition of the revenue cap method 
(3), tariffs are calculated for one regulatory period (normally 2 to 3 years) and highly impacted by efficiency factor $X$, applied to motivate the PDCs to improve efficiency of operation. If the PDC operates more efficiently and decreases costs during one regulatory period, all profit will belong to the PDC. Assuming that the PDC initially complies with efficiency factor $X$, any decrease of operation cost will be a profit to the PDC in one regulatory period. On the other hand, if the PDC is initially over efficiency factor $X$, incurring business losses, any decrease in operation cost will be a benefit to the PDC in one regulatory period. The target of this analysis is to evaluate the DAS benefits (profits) in relative units compared with the PDC's revenue or amount of EEIA.

Electric energy injected into the DN annually (EEIA) in this example is $200 \mathrm{GWh}$. Power losses in the considered DN are approximately $10 \%$, and therefore energy sold (billed) to customers is $180 \mathrm{GWh}$. Customers pay to the PDC a network charge for use of the distribution system and electric energy consumed to energy providers. The PDC's annual revenue (PRA) is based on the network charge, which in this example is approximately $\mathbf{\$ 5 , 4 0 0 , 0 0 0}$ annually (an average of 3US $\varnothing$ per kWh delivered). With PRA, the PDC has to purchase electric energy for power losses (20 GWh or $\$ 600,000$ annually with $\$ 30.00 / \mathrm{MWh})$, cover all operation costs and generate a certain profit for shareholders. Any reduction of power losses or operation costs would directly increase the PRA and profit.

DAS benefits can be differentiated as:

a) Reduction of power losses;

b) Reduction of operation costs (reduced maintenance, outage time and nonsupplied energy);

c) Reduction of network construction costs (improved utilization of facilities and postponement of investment);

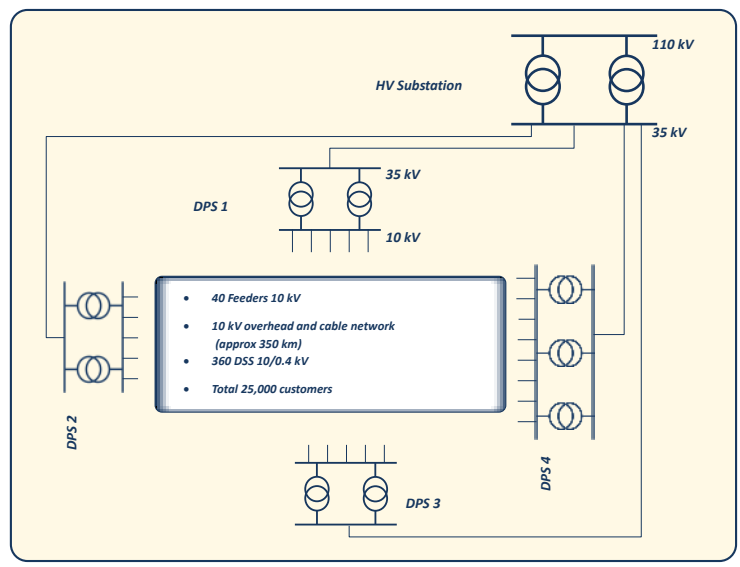

Figure 1

The example of a live Distribution Network 


\subsection{Reduction of Power Losses}

Typical breakdowns or power losses in the distribution network are presented in Fig. 2.

Optimal Feeder Reconfiguration: Power flow calculation [7]-[9], based on the real-time state estimation of the power distribution network and load profiling [10]-[12], results in power balance of network operation state, for all transformers, feeders and branches. The distribution network is operated without loops, meaning that each feeder has a certain number (or none) of "normally open switches" (NOS), providing eventual restoration of supply in the case of incidents, but normally open in the regular operation state. In large distribution networks with hundreds of feeders, there could be hundreds of NOS, providing thousands of combinations of NOS locations to open all loops. Changing the location of a NOS and keeping the network without loops is actually changing of the power flow and operating performances (loading, power losses, voltages). The target is to find the "optimal" combination of NOS locations to achieve an optimal power flow according to certain objective (minimum power losses, best voltages, reduced overloads, etc.). The typical DMS function "Optimal Feeder Reconfiguration" provides such a solution [13]-[14]. If the results are applied in the network operation, a $20 \%$ reduction of MV network power losses may be achieved, with insignificant costs of changing NOS locations [15]. Since MV network power losses are approximately $25 \%$ of total power losses, the reduction of total power losses would be $5 \%$. In terms of energy, total energy losses would be reduced 3 to $4 \%$, whereas the reduction in EEIA would be in the range of 0.3 to $0.4 \%$.

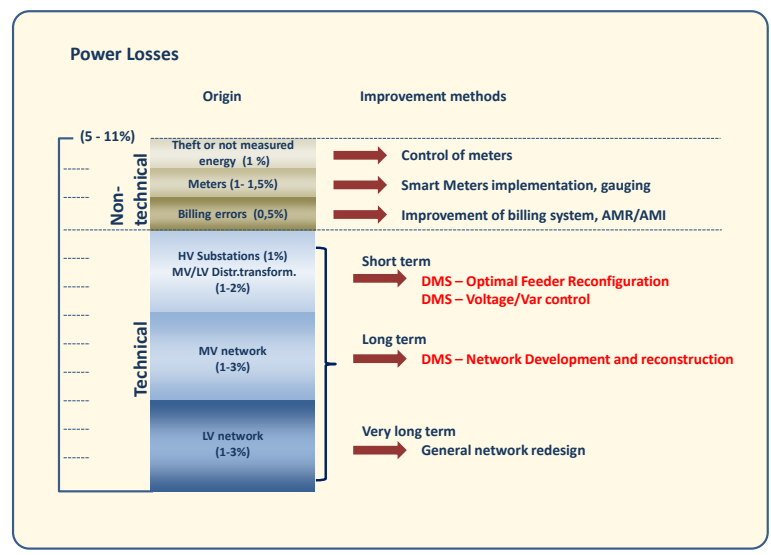

Figure 2

Breakdown of power losses 
Voltage and Var Control: DMS solutions can provide centralized (optimal) control of voltages and reactive power flow in the distribution network [16]-[19]. Based on the real-time network operation state, the DMS function "Voltage/Var Control" will calculate the "optimal" setting of the voltage regulation devices and the switching of capacitor banks applied in the distribution network, according to certain objectives (minimal voltage deviation, minimal power losses, minimal or maximal power demand, etc.). If the "minimal power losses" objective is applied, test results give an 8 to $10 \%$ reduction in MV network power losses, whereas the reduction of total power losses would be approximately $2 \%$, and the reduction of EEIA in the range 0.1 to $0.3 \%$.

Finally, the DMS functions "Optimal Feeder Reconfiguration" and "Voltage/Var Control" have to be coordinated in the field since both have an influence on the network operation state, improving voltages and reducing losses. The cumulated effect of both functions normally leads to a $25 \%$ reduction in MV network power losses, giving an approximately $6 \%$ reduction in total power losses and a $0.5 \%$ reduction in EEIA.

In the DN example, the PDC will annually purchase 6\% less energy for power losses $(1.2 \mathrm{GWh})$, which is a savings of $\$ 36,000$ annually, or $0.67 \%$ of PRA.

\subsection{Reduction of Network Operation Costs}

Nowadays, DAS is applied in a small number of utilities. Incidents (faults) and outages are resolved with a crew in the field and with a manual operation of switches, as presented in Figure 3.

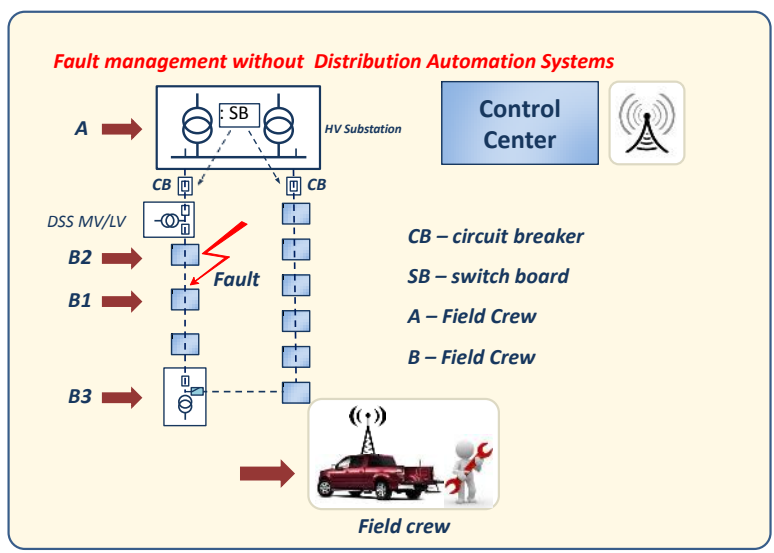

Figure 3

Fault Management without automation 
In the case of a fault on the MV feeder, one crew (A) is sent to a substation to check protection and operate feeder circuit breakers, while the second crew (B) is sent to check the fault point along the MV feeder and to manually operate the MV switches. After several operations of the circuit breaker and MV switches, the fault will be localized (B1 , B2, ...) and supply restored to non-faulty parts of the MV feeder $(B 3, \ldots)$. The whole procedure will take several hours, sometimes much longer, while customers along the feeder will suffer a long outage. Additionally, there is a high risk of wrong switching and non-optimal decisions because the operator has limited information about the fault and power loadings in the network and relies only on his experience, without technical tools to support his decisions.

In the example of the DN, the average MV feeder loading is $1 \mathrm{MW}$, and nonsupplied energy is $2 \mathrm{MWh}$ per average fault $(2 \mathrm{~h})$. An average failure rate for MV lines is in the range of 0.2 (cables) to 0.5 (overhead lines) faults $/ \mathrm{km}$, annually; therefore in the DN $(360 \mathrm{~km})$, there are approximately 150 faults/year. Energy non-supplied (ENS) is approximately $300 \mathrm{MWh}$ annually.

PDC direct outage costs: In the example of the DN, the PDC annual costs related to resolving faults in the MV network are as follows:

- Revenue lost $\$ 9,000$ (ENS=300 MWh x 3US $\varnothing / \mathrm{kWh}$ ),

- $\quad$ One Breaker failure (300 switching on fault) $\approx \$ 5,000$,

- 4 load switches failures (800 switching) $\approx \$ 16,000$,

- $\quad$ Field crew costs $(800 \times \$ 20.00 /$ switching $) \approx \$ 16,000$,

Total PDC direct outage costs $\approx \$ 46,000$.

Customers outage costs: Customers sustain damages due to power outages, the cost of which is estimated at 5 times (for households) up to 100 times (for sensitive industrial customers) the price of the delivered $\mathrm{kWh}$. In the example of the DN, the customers are $80 \%$ residential and $20 \%$ industrial, and therefore the customers outage costs will be on average 20 times the price of delivered $\mathrm{kWh}$. If customers are paying $\$ 0.08$ to $\$ 0.10 / \mathrm{kWh}$ for delivered $\mathrm{kWh}$ (network charge and energy price), the total damage to customers in the example of the DN would be $\$ 480,000$ annually (300 MWh $\times \$ 1.60 / \mathrm{kWh}$ ). Customers are not paid by the PDC directly for such damage, but this amount presents the level of real (social) damage.

Penalties paid by the PDC: The liberalization of electrical sector introduced penalties to be paid to customers in the case of outages. For example, according to regulations in Holland, utilities pay compensation of EUR 30.00 (US\$40.00) to every customer suffering an outage longer than 4 hours. In the example of the DN, $10 \%$ to $15 \%$ of outages are longer than 4 hours, and therefore PDC should pay compensation for 20 outages every year. Since each feeder has 625 customers on average, the PDC should pay approximately $\$ 500,000$ annually in compensation 
to customers. This figure is close to the real customer damage calculated in the previous chapter and demonstrates that individual compensation is estimated realistically.

Implementation of DAS: DAS would significantly improve the reliability of network operation. In the DAS project, the PDC would implement the SCADA/DMS/OMS system with remote control of each HV Substation and with MV load-switches and fault detectors at critical locations of the distribution network (Fig. 4). In this case, fault management would be significantly improved:

- HV Substations are remotely controlled and there is no need for crew A to go to the HV Substation any more,

- Critical locations in the MV distribution network are remotely controlled and equipped with fault detectors, so fault location is automated without reclosing the circuit breaker and many operations of load switches,

- If necessary, one crew (A) will go along the feeder to provide manual switching of non-remotely controlled switches and to help with supply restoration,

- Dispatchers will have DMS software for the estimation of power flow and feasible supply restoration sequence, with very small risk of wrong decisions or wrong switching steps [20],

- Outage duration will be 5 times shorter, down to 15 to 20 minutes (and if there are more RTUs in the MV network, even shorter); in addition, the ENS will decrease 5 times,

- The PDC's outage costs will be reduced because of a reduced number of switching and equipment failures in the field.

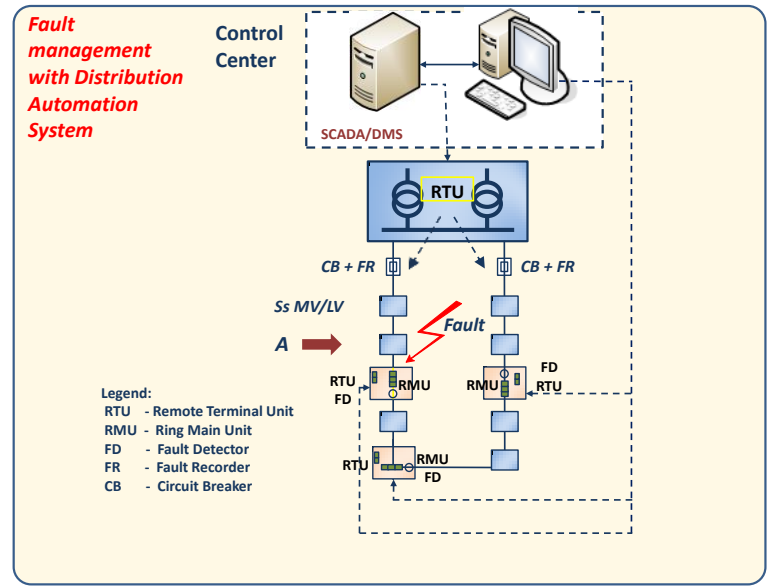

Figure 4

Fault Management after automation 
PDC direct outage costs would reduce as follows:

- Revenue lost $\$ 1,800$ (ENS = $60 \mathrm{MWh} \times 3 \mathrm{US} \notin / \mathrm{MWh}$ ),

- $\quad$ Breaker failures once in 2 years $\approx \$ 2,500$,

- $\quad$ One switch failure (300 switching) $\approx \$ 4,000$,

- $\quad$ Filed crews costs $(300 \times$ x $\$ 20 /$ switching $) \approx \$ 6,000$.

Total PDC direct outage costs $\approx \$ 14,300$

Customer outage costs would be reduced 5 times as well, due to the reduced outage time, as well as the reduced penalties paid to customers (down to $\$ 100,000$ annually).

In the DN example, savings after the DAS implementation would be in the reduced outage costs:

- $\quad$ PDC direct outage costs would be reduced $70 \%$, providing a savings of $\$ 31,700$ or $0.58 \%$ of the PRA.

- Penalties paid by the PDC (if applied) would be reduced $80 \%$, providing a savings of $\$ 400,000$ or $7.4 \%$ of the PRA.

\subsection{Reduction of Network Construction Costs}

DMS tools for network operation optimization and long-term planning analysis enable more efficient utilization of power distribution facilities and the postponement of investments in network constructions up to $20 \%$.

The construction of distribution facilities, due to new customer connections or resolving of power overloads, increases the number of distribution transformers $1 \%$ annually on average, as well as the length of power lines by $0.5 \%$. In the example of the DN, 4 new DSS and 2 kilometers of MV power lines should be built every year on average; however, with DMS, investment would be postponed and reduced to $3 \mathrm{DSS}$ and $1.6 \mathrm{~km}$ of MV power lines, giving a savings of approximately \$20,000annually.

DMS Large Area Restoration functionality enables the efficient planning of large HV supply transformer outages. The capacities of adjacent HV Substations and the available resources in the MV network are (more) efficiently utilized, consequently postponing the construction of one new HV Substation. In the example of the DN, one new HV Substation should be built every 10 years $(\$ 1,000,000$ investment); however investment can be postponed and save $\$ 30,000$ of interest.

The total reduction of network construction costs would save up to $\$ 50,000$ annually, or $0.92 \%$ of the PRA. 


\subsection{The Total DAS Benefits}

The total benefits after DAS implementation, as discussed in previous chapters, would provide an annual savings (profit) to the PDC of:

- $2 \%$ of the PRA, if the PDC is not paying compensation to customers because of outages, or up to

- $\quad 9 \%$ of the PRA, if the PDC is paying the full compensation to customers because of outages.

\section{Investment in Distribution Automation}

Investment in DAS encompasses four sectors [21]:

- SCADA/DMS Software, deployed in Distribution Control Centre (DCC), including the creation of a network model and database, operation network diagrams (schematic and geographic), delivery, training, testing and commissioning of the system.

- SCADA/DMS Hardware, deployed in DCC with (redundant) servers, communication front-end, workstations with several displays, GPS, printers, web servers, Large Screen Display, delivery, training, testing and commissioning of the system.

- Remote terminal units (RTU), implemented in HV substations and field locations (some of MV/LV substations or pole mounted switches), equipment for signal conversion (transducers, relays), ancillary equipment (power supply, relays, cabling), with assembling, delivery, training, testing and commissioning of the system.

- Communication system (radio, fiber optic, telephone leased lines), including system design, licenses for radio frequencies, delivery of equipment, delivery, training, testing and commissioning of the system.

The principle of distribution (MV network) automation is presented in Figure 5 (minimum automation to achieve a significant improvement in fault management); however detailed engineering analysis must be realized in every specific project. 


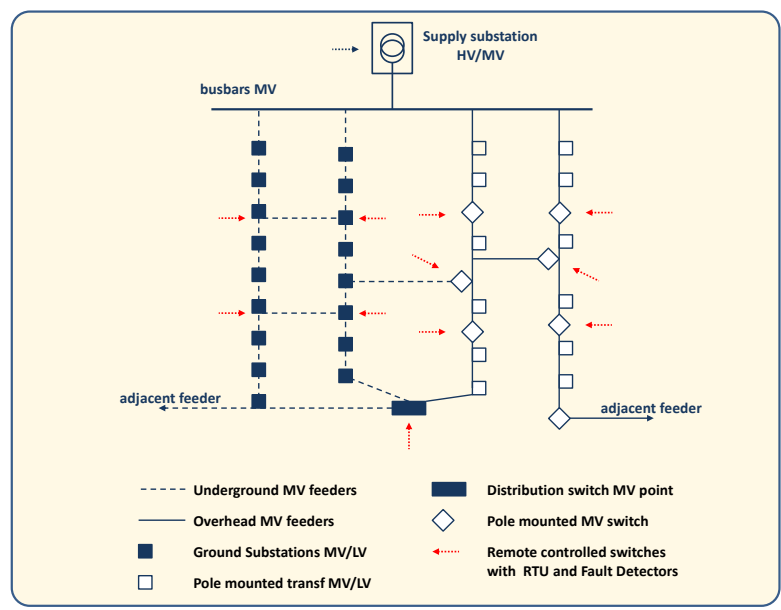

Figure 5

Principle of distribution network automation

More RTUs in the MV network will bring better results but will rapidly increase investment. Some of the DMS functions may be used for the detailed analysis and design of the optimal level of automation, keeping investment inside a limited budget. In the DN example, the following results were obtained (Figure 6):

- Each of (four) Substations $35 / 10 \mathrm{kV}$ should be automated (remotely controlled by the SCADA/DMS system),

- Approximately 25 DSS $10 / 0.4 \mathrm{kV}$ (25\% of the total number) should be automated with ring main units (RMU), RTUs and Fault Detectors. The DSSs are located on 12 underground feeders, which averages 2.5 DSS per underground feeder,

- Approximately 70 pole mounted switches (PMS) should be automated with RTUs, motor drive, local control box and Fault Detectors. PMS are located on 28 overhead $(10 \mathrm{kV})$ feeders, which averages out to 2.5 PMS per overhead feeder,

- All three of the existing distribution switching yards should be automated with RMU and RTU. 


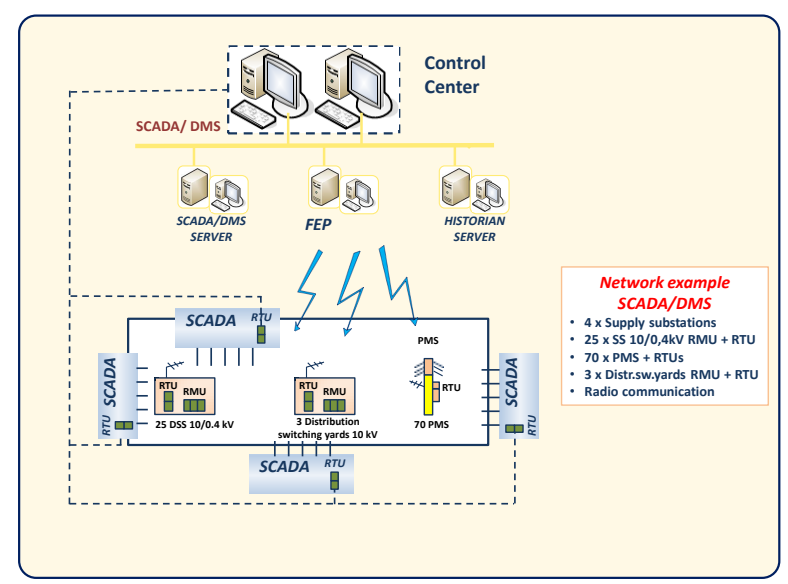

Figure 6

Optimal automation of DN

The calculation of the investment costs is presented in the Table 1.

In reality, every utility has already invested in certain automation equipment that can be included in DAS (e.g. SCADA, HV substations RTUs, and communication systems); consequently, DAS investment will actually be lower. On the other hand, there is always a certain amount of old power equipment which should be replaced in order to be included in the automation system, which will increase the investment (e.g., old manually operated air-breaking switches in the DSS should be replaced with advanced RMUs with SF6 gas and motor drives). Therefore, for the simplicity of this analysis, it is assumed that reduced investment due to existing automation equipment, equals investment in the new power equipment. The total investment in DAS in the network example is approximately $\$ 1$ million.

Table 1

DAS investments in the example of DN

\begin{tabular}{|l|c|c|r|}
\hline \multicolumn{1}{|c|}{ DAS description } & Unit price (\$) & No of units & Total price (\$) \\
\hline SCADA/DMS Software & & set & 200,000 \\
\hline Hardware in DDC & & set & 100,000 \\
\hline $\begin{array}{l}\text { Substations 35/10 kV, RTU, } \\
\text { cabling and interfaces }\end{array}$ & 50,000 & 4 & 200,000 \\
\hline $\begin{array}{l}\text { Ground substation 10/0,4 kV, } \\
\text { RTU, cabling and interfaces }\end{array}$ & 5,000 & 25 & 125,000 \\
\hline Pole mounted RTU and interfaces & 3,000 & 70 & 210,000 \\
\hline $\begin{array}{l}\text { Distribution switching yard, RTU } \\
\text { and interfaces }\end{array}$ & 10,000 & 3 & 30,000 \\
\hline $\begin{array}{l}\text { Communication system: FO } \\
\text { (interfaces) or radio system } \\
\text { (equipment, interfaces, antennas) }\end{array}$ & 1,500 & 100 & 150,000 \\
\hline
\end{tabular}




\begin{tabular}{|l|l|l|r|}
\hline Total DAS investment & & & $\mathbf{1 , 0 1 5 , 0 0 0}$ \\
\hline $\begin{array}{l}\text { The new power equipment: RMU } \\
\text { in ground substations }\end{array}$ & 8,000 & 28 & 224,000 \\
\hline $\begin{array}{l}\text { The new power equipment: PMS } \\
\text { load breakers }\end{array}$ & 4,000 & 70 & 280,000 \\
\hline $\begin{array}{l}\text { Total DAS investment with } \\
\text { replacement of power equipment }\end{array}$ & & & $1,619,000$ \\
\hline
\end{tabular}

The average DAS investment costs can be presented:

- $\quad \$ 20.000 / M W$ of the network peak load (the peak load in the example of DN is $50 \mathrm{MW}$, with a necessary investment in DAS of $\$ 1$ million),

- \$40/customer (meter) (2 $\mathrm{kW} /$ customer is the participation of individual customer load in the network peak load),

- $18 \%$ of the PRA (the PDC has an annual revenue of $\$ 5,400,000$ in the example of the DN, with necessary investment in DAS of \$1 million)

\section{Cost Benefit Analysis}

The cost/benefit analysis is made on an example of a large PDC. If a large PDC has $1000 \mathrm{MW}$ peak load, then EEIA would be approximately $4000 \mathrm{GWh} /$ year, with $3600 \mathrm{GWh}$ on the consumption side. The annual revenue of such a company (PRA) would be approximately $\$ 108$ million (M\$). If such company decides to invest in deployment of distribution automation system, total investment costs would be close to $20 \mathrm{M} \$$, with a project execution time of 2 years. Annual operation \& maintenance costs (O\&M) are typically from $2 \%$ to $3 \%$ of the investment cost and, adding 5\% for depreciation, the total annual cost of system operation would be close to $8 \%$ of the investment cost, or approximately 1.6 M\$/year. The PDC pays a certain compensation for power outages to customers, which has significant impact on the level of the DAS benefits, as discussed in chapter III of this article. Annual DAS benefits are 2\% when compensation is not paid and up to $9 \%$ of the PRA when the full compensation is paid to customers. The sensitivity of DAS benefits due to the level of compensation paid to customers will be considered.

The considered period of system operation is 10 years, which is close to the life time of the SW, HW, RTU and communication equipment. In the first step, for simplicity of analysis, actualization will be neglected. In the first year of operation, DAS will start providing savings, but the full benefits will be reached in the second year of operation.

In the cost/benefit analysis, the three following economic factors are calculated: 
$C / B=C_{t} / B_{t}$

$C / B-$ Cost/benefit factor,

$C_{t}$ - Total cost of investments and operation in a 10 -year period of consideration,

$B_{t}-$ Total benefits in 10 years of operation.

$P=B_{t} / C_{t}$

$P$ - Profitability of the project, as a ratio of total benefits and costs in 10 years of operation

$R=C_{i} / B_{t} \cdot T$

$R$ - Payback period, the period of time necessary for return of investment.

$\mathrm{Ci}$-Investment cost,

$T$ - Period of consideration, in this case 10 years.

The Cost/Benefit analysis results (without actualization) are presented in Table 2 and in Figure 7.

The total cost in 10 years of operation would be $36 \mathrm{M}$ (an investment of $20 \mathrm{M} \$$ and $\mathrm{O} \& \mathrm{M}$ costs of $16 \mathrm{M} \$$ ), whereas the total benefit would be in the range from $19 \mathrm{M} \$$ (no compensation paid to customers for outages) to $86 \mathrm{M} \$$ (the full compensation paid to customers). The DAS project will become profitable when benefits reach $4 \%$ of the PRA, which will happen when a certain (small) level of outage compensation is paid to customers by the PDC. If outage compensation is paid to the full extent, then the DAS project will have the high profitability of 2.39 and a payback period of only 2.33 years.

Table 2

Cost/Benefit analysis results - without actualization

\begin{tabular}{|l|c|c|c|c|}
\hline & Total $(\mathrm{M} \$)$ & $\mathrm{C} / \mathrm{B}$ & $\mathrm{P}$ & $\mathrm{R}$ (years) \\
\hline Investment & 20.00 & & & \\
\hline O\&M & 16.00 & & & \\
\hline Benefit 2\%PRA & 19.00 & 1.89 & 0.53 & 10.53 \\
\hline Benefit 3\%PRA & 29.00 & 1.24 & 0.81 & 6.90 \\
\hline Benefit 4\%PRA & 38.00 & 0.95 & 1.06 & 5.26 \\
\hline Benefit 5\%PRA & 48.00 & 0.75 & 1.33 & 4.17 \\
\hline Benefit 6\%PRA & 58.00 & 0.62 & 1.61 & 3.45 \\
\hline Benefit 7\%PRA & 67.00 & 0.54 & 1.86 & 2.99 \\
\hline Benefit 8\%PRA & 77.00 & 0.47 & 2.14 & 2.60 \\
\hline Benefit 9\%PRA & 86.00 & 0.42 & 2.39 & 2.33 \\
\hline
\end{tabular}




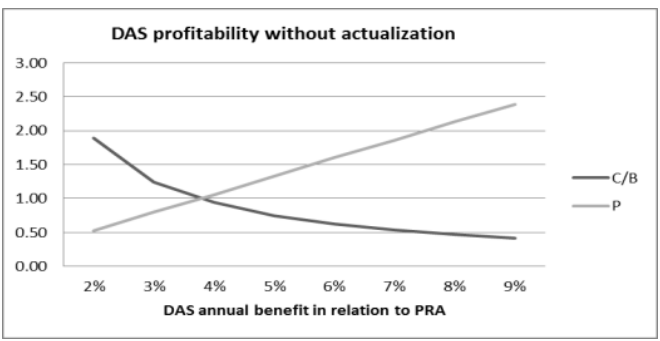

Figure 7

Profitability of DAS project without actualization

However, if actualization is not neglected, then annual benefits and costs have to be derived (recalculated) on the initial year using the actualization rate. The initial year is the first year of the system operation:

$C_{t, a}=C_{i}+\sum_{i=1}^{10} \frac{0,08 \cdot C_{i}}{(1+p)^{i}}$

$C_{t, a}$ - Total cost of investments and operation in a 10 -year period of consideration, derived in the initial year.

$p$ - actualization rate, normally $6 \%$

$B_{t, a}=\sum_{i=1}^{10} \frac{B_{i}}{(1+p)^{i}}$

$B_{t, a}$ - Total benefits in 10 years of operation, derived on the initial year.

$B_{i}-$ annual benefit in the year " $i$ "

The results of the Cost/Benefit analysis with an actualization rate of $6 \%$ are presented in Table 3 and in Figure 8.

Table 3

Cost/Benefit analysis results - with actualization $6 \%$

\begin{tabular}{|l|c|c|c|c|}
\hline & Total $(\mathrm{M} \$)$ & $\mathrm{C} / \mathrm{B}$ & $\mathrm{P}$ & $\mathrm{R}$ (years) \\
\hline Investment & 20.00 & & & \\
\hline O\&M & 11.78 & & & \\
\hline Benefit 2\%PRA & 13.78 & 2.31 & 0.43 & 14.52 \\
\hline Benefit 3\%PRA & 21.14 & 1.50 & 0.67 & 9.46 \\
\hline Benefit 4\%PRA & 27.55 & 1.15 & 0.87 & 7.26 \\
\hline Benefit 5\%PRA & 34.91 & 0.91 & 1.10 & 5.73 \\
\hline Benefit 6\%PRA & 42.27 & 0.75 & 1.33 & 4.73 \\
\hline Benefit 7\%PRA & 48.69 & 0.65 & 1.53 & 4.11 \\
\hline Benefit 8\%PRA & 56.05 & 0.57 & 1.76 & 3.57 \\
\hline Benefit 9\%PRA & 62.47 & 0.51 & 1.97 & 3.20 \\
\hline
\end{tabular}




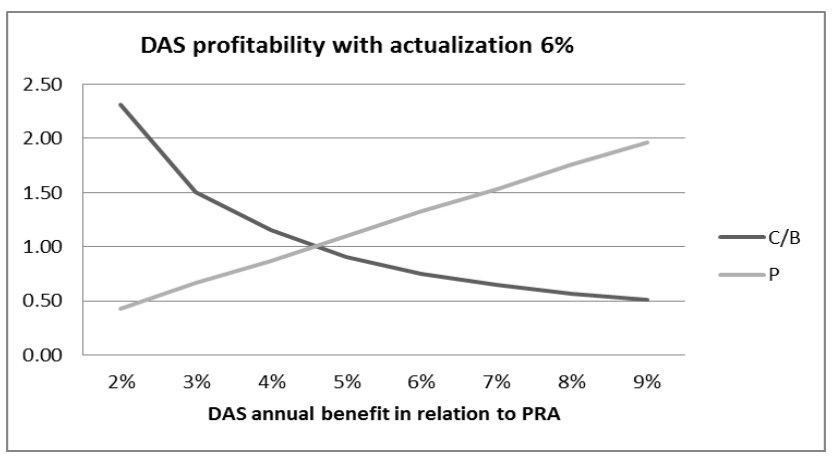

Figure 8

Profitability of DAS project with actualization

The total cost in 10 years of operation would be $31.78 \mathrm{M} \$$ (an investment of 20 $\mathrm{M} \$$ and $\mathrm{O} \& \mathrm{M}$ costs of $11.78 \mathrm{M} \$$ ), whereas the total benefit would be in the range from $13.78 \mathrm{M} \$$ (no compensation paid to customers for outages) to $62.47 \mathrm{M} \$$ (the full compensation paid to customers). The DAS project will become profitable when benefits reach $4.5 \%$ of the PRA, which will happen when a medium level of outage compensation is paid to customers by the PDC. If outage compensation is paid to the full extent, then the DAS project will have the high profitability of approximately 2 and a payback period of 3.2 years.

According to the cost/benefit analysis presented in this article, it can be concluded that DAS projects are profitable investments. Profitability depends mostly on the level of compensation which the PDC is paying to customers for non-planned outages in power network operation:

- If the PDC is not paying any compensation to customers for outages, which is unlikely, the DAS projects would hardly be profitable, but accounting other non-financial benefits, could be close to profitability,

- If the PDC is paying a certain amount, but not the full compensation, to customers for outages, the DAS projects will be profitable in the life time of the system operation, with profitability between 1 and 1.5 and a payback period between 4 and 5 years.

- If the PDC is paying appropriate (almost full) compensation to customers for outages, the DAS projects will be highly profitable, with profitability close to 2 and a payback period of approximately 3 years.

However, since the cost/benefit analysis presented in this article considers only the DAS benefits which can be precisely financially evaluated, but not all other benefits which cannot be precisely financially calculated (e.g. customer satisfaction, improvements in data management and reporting, improved simulation analysis, better setting of equipment, etc.), profitability should be even higher than calculated. 


\section{Conclusions}

Distribution Automation Systems (DAS) are advanced Smart Grid Solutions which can significantly improve the efficiency of operation of electricity distribution networks. In deregulated and open electricity markets, the Power Distribution Company (PDC) is considered as a service provider, the revenue of which comes from charges for use of the distribution network. With limited revenue, PDCs must invest in advanced technologies, known as Smart Grid Solutions, to improve the quality and reliability of supply and to reduce power losses. However, the quantification of the benefits provided by Smart Grid Solutions and the comparison with related costs is the real challenge nowadays, necessary in order to estimate the real profitability of such investments. The benefits achieved via applying DAS are analysed and evaluated in this article, using an example of a real distribution network. The DAS benefits calculated in this way are compared with the PDC's annual revenue (PRA). If the PDC is not paying any compensation to customers because of incidents, benefits are $2 \%$ of the PRA, but if the PDC is paying compensation benefits, they are up to $9 \%$ of the PRA.

Cost/Benefit analysis, made on the example of a large Power Distribution Company, reveals a good profitability from DAS implementation in a 10-year lifetime and system operation. However, since analysis cannot consider all possible benefits, because some of them cannot be precisely financially evaluated, the real profitability of the DAS implementation should be even higher. The general conclusion is that distribution automation projects are profitable investments.

\section{References}

[1] L. Philipson, H. Lee Willis, Understanding Electric Utilities and DeRegulation (Marcel Dekker Inc., 1999)

[2] S. Stoft, Power System Economics (Wiley, 2002)

[3] D. Kirschen, G. Strbac, Power System Economics (John Wiley \& Sons, 2004)

[4] N. Katic, V. Borozan, S. Halilcevic, Power System Economics (EU project Cost Effective and Environmental Friendly Energy Systems - CEFES TEMPUS Programme CD_JEP-18126-2003, 2007)

[5] Energy Agency of Republic of Serbia, Access to and Use of System Charging Methodology for Electricity Distribution (http://www.aers.rs/Files/Metodologije/Preciscen/Eng/2008-12-

22_MetodologijaDistribucijaEEPrecisceniTekst.pdf ,2010)

[6] H. T. Ylvisaker, The future Network Company - a Norewegian perspective, Distributech Europe Conference, November 2000, Vienna, Austria

[7] D. Sirmohammadi, H. W.Hong, A. Semlyen, G. X. Luo, A Compensationbased Power Flow Method for Weakly Meshed Distribution and Transmission Networks, IEEE Trans. on Power System, Vol. 3, No. 2, May 1988, pp. 753-762 
[8] S. Cheng, D. Shirmohammadi, A Three-Phase Power Flow Method for Real-Time Distribution System Analysis; IEEE Trans. on Power System, Vol. 10, No. 2, May 1995, pp. 671-679

[9] G. X. Luo, A. Semlyen, Efficient Load Flow for Large Weekly Meshed Distribution and Transmission Network; IEEE Trans. on Power System, Vol. 5, No. 4, November 1990, pp. 1309-1316

[10] I. Roytelman; S. M. Shahidehpour, State Estimation for Electric Power Distribution Systems in Quasireal-time Conditions, IEEE Trans. on Power Delivery, Vol. 8, No. 4, October 1993, pp. 2009-2015

[11] M. E. Baran, A. W. Kelley, State Estimation for Real-Time Monitoring of Distribution Systems in Quasi Conditions; IEEE Trans. on Power System, Vol. 9, No. 3, August 1993, pp. 1601-1609

[12] C. N. Lu, J. H. Teng, W.-H. E. Liu, Distribution System State Estimation; IEEE Trans. on Power System, Vol. 10, No. 1, February 1995, pp. 229-240

[13] I. Roytelman, V. Melnik; S. S. H. Lee, R. L. Lugtu, Multi-Objective Feeder Reconfiguration by Distribution Management System; IEEE Trans. on Power System, Vol. 11, No. 2, May 1996, pp. 661-667

[14] M. E. Baran, F. F. Wu, Network Reconfiguration in Distribution Systems for Loss Reduction and Load Balancing, IEEE Trans. On Power Delivery, Vol. 4, No. 2, April 1989

[15] Giorgio di Lembo, Paola Petroni, Christian Noce, Reduction of Power Losses and $\mathrm{CO}_{2}$ Emission: Accurate Network Data to Obtain Good Performances of DMS Systems, CIRED $20^{\text {th }}$ Conference Prague, June 8-11, 2009, Prague, Czech Republic

[16] I. Roytelman, B. K. Wee, R. L. Lugtu, Volt/Var Control for Modern Distribution Management System, IEEE Trans. on Power System, Vol. 10, No. 3, August 1995, pp. 1454-1460

[17] I. Roytelman, B. K. Wee, R. L. Lugtu, T. M. Kulas, T. Brossart, Pilot Project to Estimate the Centralized Volt/Var Control Effectiveness, IEEE Trans. on Power System, Vol. 13, No. 3, August 1998

[18] V. Strezoski, N. Katic, D. Janjic, Voltage Control Integrated in Distribution Management Systems, Electric Power Systems Research, No. 60, 2001, pp. $85-97$

[19] A. Hamouda, K. Zehar, Improvement of the Power Transmission of Distribution Feeders by Fixed Capacitor Banks, Acta Polytechnica Hungarica, Vol. 4, No. 2, 2007, pp. 47-62

[20] D. S. Popovic, R. M. Ciric, A Multi-Objective Algorithm for Distribution Networks Restoration, IEEE Trans. on Power Delivery, Vol. 16, No. 3, July 1999, pp. 1134-1141

[21] N. Katic, V. Strezoski, D. Popovic, Business Benefits of DMS Software Application in Competitive Distribution, CIRED $17^{\text {th }}$ Conference Barcelona, Session 6, 2003, Barcelona, Spain 